\title{
The oldest representative of the bombyliid bee fly in the earliest Eocene French amber
}

\author{
Aude Maheu and Andre Nel \\ Acta Palaeontologica Polonica 65 (1), 2020: 81-83 doi:https://doi.org/10.4202/app.00657.2019
}

Eoconophorina delfineae gen. et sp. nov., the oldest representative of the bee fly subfamily Bombyliinae, is described from the earliest Eocene Oise amber (France). It is characterized by the presence of mid tibial spurs, cylindrical abdomen and a particular combination of wing venation characters. It is putatively attributed to the tribe Conophorini. This fossil is $53 \mathrm{Ma}$ old, ca. $19 \mathrm{Ma}$ older than the previous oldest records of the subfamily, known as compression fossils. There are very few older bee flies, one from the Paleocene of Menat (France), and six from the mid-Cretaceous Burmese amber, belonging to different subfamilies or of uncertain taxonomic position. Thus this fossil will be helpful for future calibration of phylogeny and dating of the bee flies.

Aude Maheu [aude.maheu23@gmail.com], 5 rue Marie Davy, F-75014, Paris, France. André Nel [anel@mnhn.fr] (corresponding author), Institut Systématique Evolution Biodiversité (ISYEB), Muséum national d'Histoire naturelle, CNRS, Sorbonne Université, Université des Antilles, EPHE, 57 rue Cuvier, CP 50, F-75005 Paris, France.

This is an open-access article distributed under the terms of the Creative Commons Attribution License (for details please see creativecommons.org), which permits unrestricted use, distribution, and reproduction in any medium, provided the original author and source are credited. 